\title{
PENGARUH KEDISIPLINAN SISWA TERHADAP HASIL BELAJAR FISIKA DI KELAS $X$
}

\author{
Aminatussaadah $^{1}$, Mahdiyyah Daeng Hanafi ${ }^{2}$, Shella Maryani ${ }^{3}$ \\ 1,2,3 Universitas Jambi \\ ${ }^{1}$ aminatussaadah94@gmail.com, ${ }^{2}$ diyyah2817@gmail.com, \\ ${ }^{3}$ shellamaryani27@gmail.com
}

\begin{abstract}
Abstrak
Penelitian ini bertujuan untuk mengetahui pengaruh sikap kedisiplinan siswa terhadap hasil belajar fisika di kelas X SMA Negeri 3 Kota Sungai Penuh. Cara belajar yang efektif dan efisien sangat bisa dilakukan oleh siswa jika siswa memiliki kedisiplinan yang baik. Penelitian ini menggunakan teknik kuantitatif dengan analisis deskriptif. Data diperoleh dari hasil penyebaran angket sebanyak 46 butir dan soal sebanyak 27 butir. Peneliti melakukan pengambilan sampel dengan teknik random sampling dan didapat sampel sebanyak 30 dari 90 populasi siswa kelas X SMA Negeri 3 Kota Sungai Penuh. Data diolah dengan menggunakan analisis statistik berupa uji normalitas, uji homogenitas, dan uji korelasi. Didapatkan hasil bahwa pengaruh sikap kedisiplinan siswa terhadap hasil belajar fisika di kelas X SMA Negeri 3 Kota Sungai Penuh yaitu signifikan positif dengan kategori "cukup". Dari hasil yang telah diperoleh peneliti mengharapkan agar guru dan warga sekolah dapat meningkatkan kedisiplinan siswa, sehingga dapat mempengaruhi hasil belajar siswa menjadi lebih baik.
\end{abstract}

Kata Kunci: Penelitian; Kedisiplinan; Hasil Belajar.

\begin{abstract}
This study aims to determine the effect of student discipline on learning outcomes in physics class X SMA Negeri 3 Sungai Penuh City. How to learn that is effective and efficient can be done by students if students have good discipline. This research uses quantitative techniques with descriptive analysis. The data were obtained from the results of distributing questionnaires as many as 46 items and as many as 27 items. Researchers took samples using random sampling techniques and obtained a sample of 30 of the 90 population of class X SMA Negeri 3 Sungai Penuh City. The data were processed using statistical analysis in the form of normality test, homogeneity test, and correlation test. The results showed that the effect of student discipline towards learning outcomes in physics class X SMA Negeri 3 Kota Sungai Penuh is significant positively with the "sufficient" category. From the results obtained, the researcher hopes that teachers and school members can improve student discipline, so that it can affect student learning outcomes for the better.
\end{abstract}

Keywords: Research; Discipline; Learning Outcomes. 
Edutainment : Jurnal Ilmu Pendidikan dan Kependidikan

Volume 8 Nomor 2 Edisi Juli-Desember 2020

\section{PENDAHULUAN}

Menurut (Kurniawan, Astalini, Kurniawan, \& Pathoni, 2019), pendidikan merupakan kegiatan yang sangat penting bagi semua individu, karena pendidikan mampu merubah tingkah laku dan pengetahuan individu menjadi lebih baik. Juga di jelaskan oleh (Ningsi \& Nasih, 2020) Pendidikan merupakan proses yang terjadi secara berkelanjutan yang memiliki tujuan untuk meningkatkan kualitas sumber daya manusia. Pendidikan adalah upaya sadar dan terencana untuk menciptakan sebuah suasana belajar dan proses pembelajaran agar siswa aktif mengembangkan potensinya (Maison, Darmaji, Kurniawan, Dewi, \& Kartina, 2019). Pendidikan merupakan aktivitas penting di proses pembelajaran (Kurniawan, Astalini, \& Sari, 2019). Pembelajaran adalah aktivitas guru untuk menciptakan kondisi yang memungkinkan proses belajar siswa secara berkala, secara singkat pembelajaran adalah proses membuat orang belajar. Pada dasarnya belajar adalah suatu proses untuk mengubah tingkah laku (Aminoto \& Pathoni, 2014). Belajar sebenarnya merupakan lebih dari sekadar proses menghafal dan menumpuk ilmu pengetahuan, tetapi juga bagaimana pengetahuan yang diperoleh siswa bermakna melalui keterampilan berpikir dan bereksperimen (Aminoto, Dani, \&
Lestari, 2020). Dengan pendidikan dapat meningkatkan kualitas diri dari setiap individu (Darmaji, et al., 2020). Pendidikan merupakan ujung tombak dalam pengembangan sumberdaya manusia, sehingga pendidikan harus berperan aktif dalam meningkatkan kualitas dan kuantitas pola pikir peserta didik (Utama, Maison, \& Syarkowi, 2018). Sistem pendidikan yang terlalu lebih mementingkan aspek kognitif, dengan proses pembelajaran yang pasif dan kaku (Mayasari, Syamsurizal, \& Maison, 2015).

Dalam tingkat pendidikan sekolah menengah atas, mempelajari berbagai ilmu pengetahuan, salah satu ilmu yang di pelajari ialah ilmu fisika (Astalini, Kurniawan, Perdana, \& Pathoni, 2019). Fisika adalah ilmu yang berhubungan dengan kehidupan sehari-hari dengan rumus dan konsep ilmiah (Maison, et al., 2020). Fisika merupakan pembelajaran dengan ilmu pengetahuan yang membahas gejala-gejala dan sifat-sifat pada benda yang berada di alam (Darmaji, Kurniawan, Astalini, \& Nasih, 2019). Mempelajari fisika pada dasarnya merupakan menguasai produk fisika yang berupa kumpulan hukum, teori, prinsip, aturan, dan rumusrumus yang terbangun oleh konsep-konsep sesuai proses pengkajiannya (Hendri, Pramudya, \& Pratiwi, 2019). Pembelajaran Fisika di SMA bertujuan untuk melatih siswa berpikir ilmiah dengan menggunakan 


\section{Edutainment : Jurnal Ilmu Pendidikan dan Kependidikan}

Volume 8 Nomor 2 Edisi Juli-Desember 2020

metode ilmiah serta menghubungkan materi fisika dengan permasalahan fisika yang ada dalam kehidupan sehari-hari. Pembelajaran fisika yang berpacu pada konsep-konsep memerluan pemahaman yang tinggi. Terkadang, satu guru tidak dapat mengimbangi banyaknya siswa di kelas (Putri, Maison, \& Darmaji, 2018). Pembelajaran fisika menuntut siswa aktif dalam proses pembelajaran (Darmaji, Kurniawan, Parasdila, \& Irdianti, 2018). Sejak duduk di bangku sekolah menengah, fisika merupakan mata pelajaran yang menakutkan (Pathoni, Rohati, \& Nazarudin, 2015). Pelajaran fisika masih diangap sebagian siswa sebagai pelajaran yang tidak menarik dan sulit untuk dipahami (Purwanto, Hendri, \& Susanti, 2016).

Sikap siswa itu penting, akan tetapi tidak hanya siswa saja yang berperan pentig dalam pencapaian sikap positif terhadap pelajaran fisika. Tetapi juga guru sebagai subjek terlihat dalam proses pendidikan dan pembelajaran (Hardiyanti, Astalini, \& Kurniawan, 2018). Penilaian afektif tidak dapat dilakukan setiap saat (dalam arti pengukuran formal), karena perubahan tingkah laku peserta didik dapat berubah sewaktu-waktu (Maison, Astalini, Sholihah, \& Kurniawan, 2018). Sikap merupakan salah satu faktor yang mempengaruhi proses pembelajaran yang berasal dari dalam diri siswa (Maison,
Astalini, Kurniawan, \& Sholihah, 2018). Aspek sikap yang tidak kalah penting terhadap IPA yaitu bagaimana siswa mampu melakukan pembelajaran mandiri melalui penyelidikan konsep IPA secara langsung (Astalini, Kurniawan, \& Kurniawan, Analisis Sikap Siswa Terhadap IPA Di SMP Kabupaten Muaro Jambi, 2020). Sikap merupakan tanda ekspresi siswa terhadap pembelajaran (Kurniawan D. A., Astalini, Kurniawan, \& Anggraini, 2019).

Usaha meningkatkan hasil belajar fisika dapat dilakukan dengan memperbaiki proses pembelajaran. Proses pembelajaran merupakan sekumpulan kegiatan dan serangkaian pengalaman yang dihadirkan oleh pendidik kepada peserta didiknya. Menurut Rijal \& Bachtiar (2015) keberhasilan proses pembelajaran tentunya akan dipengaruhi oleh berbagai faktor baik dari lingkungan sekolah, keluarga ataupun dari siswa itu sendiri. Siswa sebagai orang yang sedang belajar dan berkembang memiliki keunikan dan karakter masingmasing dalam proses pembelajaran. Keunikan yang dimiliki membuat siswa memiliki respon yang berbeda dalam memahami suatu pelajaran. Baik dari segi sikap ataupun gaya belajar yang menunjang keberhasilan belajarnya.

Kedisiplinan siswa yang baik akan mempengaruhi hasil belajar siswa. Disiplin berangkat sekolah dan mengikuti pelajaran, 


\section{Edutainment : Jurnal Ilmu Pendidikan dan Kependidikan}

Volume 8 Nomor 2 Edisi Juli-Desember 2020

disiplin menaati peraturan yang ada di sekolah, dan disiplin mengerjakan tugas terutama tugas pekerjaan rumah (Alimaun, 2015). Menurut Sobri \& Moerdiyanto (2014) bahwa hasil belajar menunjukkan tingkat kemampuan dan penguasaan kompetensi dari setiap mata pelajaran yang bersifat esensial dan fungsional bagi siswa, sehingga memungkinkan bagi mereka untuk belajar lebih lanjut dalam rangka pembentukan kepribadian. Dengan kemampuan tersebut, siswa dapat menyelesaikan masalah-masalah berkaitan dengan sosial ekonomi yang dihadapi dalam kehidupan bermasyarakat secara rasional dan bertanggung jawab, serta mengambil keputusan dengan mempertimbangkan nilai-nilai positif dalam masyarakat yang majemuk.

Menurut Ariananda, Hasan, \& Rakhman (2014) sikap kedisiplinan penting dan harus dimiliki oleh setiap siswa. Disiplin membantu siswa dalam proses pembentukan sikap, prilaku, dan akan mengantar seorang siswa sukses dalam belajar dan ketika bekerja nanti. Sejalan dengan penelitian yang dilakukan oleh Haryono (2016) keberhasilan siswa dalam studinya dipengaruhi oleh cara belajarnya. Siswa yang memiliki cara belajar yang efektif memungkinkan untuk mencapai hasil atau prestasi yang lebih tinggi daripada siswa yang tidak mempunyai cara belajar yang efektif.
Berdasarkan uraian di atas, tujuan dilakukannya penulisan artikel ini yaitu untuk mengetahui bagaimana pengaruh kedisiplinan siswa terhadap hasil belajar di kelas X. Setiap siswa yang memiliki cara belajar yang efektif dan sangat memungkinkan untuk mencapai hasil dan prestasi yang lebih tinggi daripada siswa yang tidak memiliki cara belajar yang efektif. Cara belajar yang efektif dan efisien sangat bisa dilakukan oleh siswa yang mempunyai kedisiplinan yang baik. Siswa yang disiplin dalam belajarnya akan berusaha mengatur serta menggunakan strategi dan cara yang tepat baginya. Kebiasaan belajar siswa dipengaruhi oleh kebiasaan siswa dalam belajar di sekolah, di rumah maupun di masyarakat (Putri, Maison, \& Darmaji, 2018).

\section{METODE PENELITIAN}

\section{Jenis Penelitian}

Pada penilitian ini menggunakan metode deskriptif kuantitatif yang dilakukan dengan penyebaran angket dan soal kepada siswa kelas X SMAN 3 Kota Sungai Penuh. Setelah dilakukan penyebaran angket dan soal data dianalisis secara kuantitatif menggunakan statistik deskriptif. Menurut Hamdi \& Bahruddin (2014) Penelitian deskriptif (descriptive Research) merupakan suatu metode penelitian yang ditunjukan untuk menggambarkan fenomena-fenomena yang ada, yang berlangsung pada saat ini atau 
Edutainment : Jurnal Ilmu Pendidikan dan Kependidikan

Volume 8 Nomor 2 Edisi Juli-Desember 2020

saat yang lampau. Salah satu prinsip terpenting dalam penelitian kuantitatif yaitu memperhitungkan berbagai sumber variabilitas, dimana variabilitas menunjukan seberapa jauh observasi yang dilakukan peneliti, sebelum melaksanakan tahapan-tahapan peneitian.

\section{Waktu dan Tempat Penelitian}

Penelitian dilakukan pada tanggal 30 September 2020 sampai dengan 10 Oktober 2020 pada kelas X Mipa SMAN 3 Kota Sungai Penuh.

\section{Subjek Penelitian}

Subjek penelitian terdiri dari 30 siswa terdiri dari kelas X SMAN 3 Kota Sungai Penuh. Teknik pengambilan sampelnya adalah random sampling.

\section{Instrumen Penelitian}

Intrumen penelitian ini menggunakan angket penelitian dari (Hatmoko, 2017) yang telah lulus uji validitas dan reliabilitas. Menurut (Waluya, 2009), angket adalah alat pengumpul data untuk kepentingan penelitian, angket digunakan dengan mengedarkan formulir yang berisi beberapa pernyataan kepada beberapa subjek (responden) untuk mendapat tanggapan secara tertulis. Angket terdiri dari 46 pernyataan dengan menggunakan skala likert, sedangkan soal sebanyak 27 butir. Skala likert merupakan skala yang mengukur kesetujuan atau ketidaksetujuan sesorang terhadap serangkaian pernyataan berkaitan dengan keyakinan atau perilaku mengenai suatu objek tertentu (Hermawan, 2005). Skala tersebut terdiri dari 4 poin skala, yakni 4 sangat setuju, 3 setuju, 2 tidak setuju, dan 1 sangat tidak setuju.

\section{Prosedur Penelitian}

Penelitian dimulai dengan menghubungi wali kelas dari sekolah tersebut, dikarenakan sedang pandemi, peneliti menggunakan angket online. Dengan bantuan wali kelas, peneliti membagikan angket dan soal kepada siswa untuk diisi. Kemudian data tersebut diolah dan dianalisis.

\section{Teknik Analisis Data}

Data dianalisis dengan menggunakan software SPSS dan dilakukan beberapa uji, antara lain: uji normalitas, uji homogenitas, dan uji korelasi. Untuk menggambarkan data pengaruh kedisiplinan siswa terhadap hasil belajar fisika, maka statistik yang digunakan yaitu deskriptif kuntitatif.

\section{HASIL DAN PEMBAHASAN}

Dari hasil penelitian yang telah dilaksanakan berupa penyebaran angket secara online kepada siswa kelas X Mipa SMA Negeri 3 Kota Sungai Penuh. Di ambil sampel sebanyak 30 dari 90 populasi dengan teknik random sampling. Berikut ini hasil dari penyebaran angket kedisiplinan dan tes soal hasil belajar.

\section{Uji Normalitas}

Menurut (Santoso, 2010) tujuan uji normalitas yaitu ingin mengetahui apakah distribusi sebuah data mengikuti atau 
Edutainment : Jurnal Ilmu Pendidikan dan Kependidikan

Volume 8 Nomor 2 Edisi Juli-Desember 2020

mendekati distribusi normal, yakni distribusi data dengan bentuk lonceng (bell shaped). Menurut (Sahab, 2012) jika signifikansi di bawah 0,05 berarti terdapat perbedaan signifikansi, dan jika sigfikansi di atas 0,05 maka tidak terjadi perbedaan yang signifikan.

Tabel 1. Statistik Uji Normalitas Kedisiplinan dan Hasil Belajar Siswa Kelas X Mipa

\section{Tests of Normality}

\begin{tabular}{lllllll}
\hline & \multicolumn{3}{l}{$\begin{array}{l}\text { Kolmogorov- } \\
\text { Smirnov }\end{array}$} & & \multicolumn{3}{l}{ Shapiro-Wilk } \\
\cline { 2 - 7 } & $\begin{array}{l}\text { Statist } \\
\text { d }\end{array}$ & Sig & Statist & d & Sig \\
& ic & f &. & ic & f &. \\
\hline Kedisiplin & \multirow{2}{*}{150} & 3 & .08 & \multirow{2}{*}{.919} & 3 & .02 \\
an & & 0 & 2 & & 0 & 5 \\
Hasil & \multirow{2}{*}{.156} & 3 & .05 & & 3 & .01 \\
belajar & & 0 & 9 & .905 & 0 & 1 \\
\hline
\end{tabular}

a. Lilliefors Significance Correction

Berdasarkan tabel 1. Statistik Uji Normalitas Kedisiplinan dan Hasil Belajar Siswa Kelas X Mipa di SMAN 3 Kota Sungai Penuh diperoleh data KolmogorovSmirnov pada kedisiplinan nilai statistiknya 0.150, degree of freedom bernilai 30 dan signifikansi bernilai 0.082. Data Kolmogorov-smirnov untuk hasil belajar nilai statistiknya sebesar 0.156 , degree of freedom bernilai 30 dan signifikansinya bernilai 0.059. Sedangkan Data pada Saphiro-Wilk, kedisiplinan memiliki statistik bernilai 0.919 , degree of freedom bernilai 30 dan signifikansinya 0.025 . Sedangkan data Shapiro-Wilk pada hasil belajar siswa memiliki nilai statistik 0.905 , degree of freedom bernilai 30 dan signifikansinya bernilai 0.011. Uji Normalitas pada sig Kolmogorov-Smirnov untuk melihat data yang lebih dari 30 responden dan melihat data Saphiro-Wilk untuk data yang kurang dari 30 responden (Sukarni, 2020).

Oleh karena itu, pada penelitian ini, uji normalitas melihat pada data KolmogorovSmirnov, karena jumlah sampel sebanyak 30. Nilai signifikansi berdasarkan uji normalitas di atas pada KolmogorovSmirnov menunjukkan nilai lebih besar dari 0.05. Maka data kedisiplinan dan hasil belajar siswa dapat dinyatakan terdistribusi "Normal".

\section{Uji Homogenitas}

Peneliti yang bertujuan untuk membandingkan dua kelompok data atau lebih terlebih dahulu harus melakukan uji kesamaan keragaman atau uji kesamaan varian kelompok data yang bisa disebut uji homogenitas (Simanjuntak, 2020). Sebagai kriteria pengujian, jika nilai signifikansi lebih dari 0.05, maka dapat dikatakan bahwa varian dari dua atau lebih kelompok data sama (Gunawan, 2020).

Tabel 2. Statistik Uji Homogenitas Kedisiplinan dan Hasil Belajar Siswa kelas X Mipa

Test of Homogeneity of Variances Levene

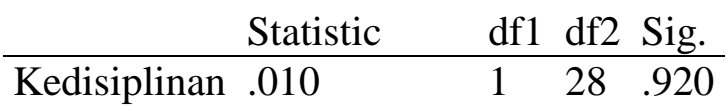

Hasil belajar .812 
Edutainment : Jurnal Ilmu Pendidikan dan Kependidikan

Volume 8 Nomor 2 Edisi Juli-Desember 2020

Berdasarkan tabel 2 statistik uji homogenitas kedisiplinan dan hasil belajar siswa kelas X Mipa di SMAN 3 Kota Sungai Penuh, diperoleh data kedisiplinan dengan nilai statistik sebesar 0.010, degree of freedom (df1) bernilai 1, degree of freedom (df2) bernilai 28 dan siginifikansi pada kedisiplinan siswa 0.920. Pada data hasil belajar siswa didapatakan nilai statistik sebesar 0.812, degree of freedom (df1) bernilai 1, degree of freedom (df2) bernilai 28 dan didapat nilai signifikansi hasil belajar siswa 0.375. Dua data tersebut memiliki nilai signifikansi yang lebih besar dari 0.05 maka dapat dinyatakan data kedisplinan dan hasil belajar siswa merupakan data "homogen".

\section{Uji Korelasi}

Uji korelasi merupakan analisis statistik untuk melihat hubungan antara dua variabel dengan data numerik. Uji korelasi dapat menentukan arah dan kekuatan hubungan antar dua variabel yang diuji. Pada uji korelasi akan diketahui, apakah peningkatan nilai variabel bebas juga akan diikuti oleh peningkatan nilai variabel terikat, atau penurunannya. Nilai p (sig) menentukan apakah hubungan bermakna atau tidak yang mana hubungan antar variabel dikatakan bermakna bila $\mathrm{p}<0.05$ (Hardisman, 2020).

Menurut Arikunto dalam (Hardisman, 2020) intrepetasi nilai r (correlation coefficient) berdasarkan rentang nilai: $\mathrm{r}=$
0,00 s / d <0,20: Sangat Rendah; $r=0,20$ s / d <0,40: Rendah; $\mathrm{r}=0,40 \mathrm{~s} / \mathrm{d}<0,60$ : Cukup; $\mathrm{r}=0,60 \mathrm{~s} / \mathrm{d}<0,80$ : Tinggi; $\mathrm{r}=0,80$ s / d <1,0: Sangat Tinggi.

Tabel 3. Statistik Uji Korelasi Kedisiplinan dan Hasil Belajar Siswa

\section{Correlations}

\begin{tabular}{|c|c|c|c|}
\hline & & $\begin{array}{l}\text { kedisiplin } \\
\text { an }\end{array}$ & $\begin{array}{l}\text { hasil } \\
\text { belaja } \\
\mathrm{r}\end{array}$ \\
\hline \multirow[t]{3}{*}{$\begin{array}{l}\text { Kedisiplin } \\
\text { an }\end{array}$} & $\begin{array}{l}\text { Pearson } \\
\text { Correlati } \\
\text { on }\end{array}$ & 1 & $.551^{*}$ \\
\hline & $\begin{array}{l}\text { Sig. (2- } \\
\text { tailed) }\end{array}$ & & .002 \\
\hline & $\mathrm{N}$ & 30 & 30 \\
\hline \multirow{4}{*}{$\begin{array}{l}\text { Hasil } \\
\text { belajar }\end{array}$} & Pearson & & \\
\hline & $\begin{array}{l}\text { Correlati } \\
\text { on }\end{array}$ & $.551^{* *}$ & 1 \\
\hline & $\begin{array}{l}\text { Sig. } \\
\text { tailed) }\end{array}$ & .002 & \\
\hline & $\mathrm{N}$ & 30 & 30 \\
\hline
\end{tabular}

Berdasarkan tabel statistik uji korelasi Kedisiplinan dan Hasil Belajar Siswa Kelas X Mipa di SMAN 3 Kota Sungai Penuh didapatkan data hubungan antara kedisiplinan dengan hasil belajar siswa dengan nilai pearson correlation 0.551 dan dengan nilai signifikansinya 0.002. Maka dapat dikatakan bahwa pengaruh kedisiplinan terhadap hasil belajar fisika di X Mipa SMA Negeri 3 Kota Sungai Penuh bermakna positif dengan kategori kekuatan hubungan "Cukup". 
Edutainment : Jurnal Ilmu Pendidikan dan Kependidikan

Volume 8 Nomor 2 Edisi Juli-Desember 2020

Tujuan dilakukannya penelitian ini untuk mengetahui pengaruh sikap disiplin dalam pembelajaran Fisika di sekolah. Menurut (Dwijanti, 2014), pembelajaran IPA khususnya materi fisika sebagian besar masih disajikan sebagai konsep dan kumpulan rumus yang harus dihafalkan, guru lebih dominan menyampaikan materi dan kurang memberi kesempatan siswa untuk berpartisipasi aktif dalam proses pembelajaran. Penelitian yang melakukan penanaman karakter disiplin terhadap pembelajaran IPA tersebut agar siswa lebih dapat belajar untuk menemukan sikap itu sendiri antar lain, yakni sikap jujur, teliti, tanggung jawab, dan rasa ingin tahu terhadap suatu kedisiplinan terhadap siswa dan masyarakat sekitar. Sikap yang diharapkan adalah sikap objektif, jujur, menghargai pendapat orang lain. Yang mana kedisiplinan ini harus lebih ditingkatkan dan apabila sudah baik harus dipertahankan. Oleh karena itu, akan lebih baik jika guru menanamkan sikap disiplin kepada siswa agar siswa dapat belajar dengan lebih baik dan efisien, sehingga meningkatkan hasil belajarnya.

\section{SIMPULAN DAN SARAN}

Berdasarkan penelitian yang sudah berlangsung, terlihat pada tabel 3. Statistik Uji Korelasi Kedisiplinan dan Hasil Belajar Siswa kelas X Mipa di SMAN 3 Kota Sungai Penuh, didapatkan hasil yang postif dengan kategori kekuatan pengaruh “cukup". Maka dapat disimpulkan bahwa kedispilinan sangat berpengaruh besar terhadap hasil belajar siswa. Siswa yang memiliki sikap disiplin yang tinggi, maka siswa tersebut akan mendapatkan hasil belajar yang tinggi, sedangkan siswa yang memiliki sikap disiplin yang kecil, maka siswa akan mendapatkan hasil belajar yang kecil.

Penulis menyadari penulisan artikel ini belum maksimal, masih terdapat beberapa kesalahan yang dilakukan oleh penulis. Maka dari itu, penulis berharap peneliti selanjutnya dapat mengembangkan penelitian dengan menambahkan variabel penelitian yang dilaksanakan oleh penulis.

\section{DAFTAR PUSTAKA}

Alimaun, I. (2015). Pengaruh Kedisiplinan terhadap Hasil Belajar Siswa Sekolah Dasar se-Daerah Binaan R. A. Kartini Kecamatan Kutoarjo Kabupaten Purworejo. Skripsi: Universitas Negeri Semarang.

Aminoto, T., \& Pathoni, H. (2014). Penerapan Media E-Learning Berbasis Schoology untuk Meningkatkan Aktivitas dan Hasil Belajar Materi Usaha dan Energi di Kelas XI SMAN 10 Kota Jambi. Jurnal Sainmatika, 8(1), 13-29.

Aminoto, T., Dani, R., \& Lestari, N. (2020, Juni). Penerapan Inovasi Termometer Gas Sebagai Media Pembelajaran Fisika di SMAN 3 dan SMAN 5 Sungai Penuh. Jurnal Karya Abdi Masyarakat, 4(1), 54-62.

Astalini, Kurniawan, D. A., \& Kurniawan, N. (2020). Analisis Sikap Siswa terhadap IPA di SMP Kabupaten Muaro Jambi. Jurnal Pendidikan Sains, 8(1), 18-26. 
Astalini, Kurniawan, D. A., Perdana, R., \& Pathoni, H. (2019). Identifikasi Sikap Peserta Didik terhadap Mata Pelajaran Fisika di Sekolah. Unnes Physics Education Journal, 8(1), 34-43.

Darmaji, Astalini, Kurniawan, D. A., Ningsi, A. P., Romadona, D. D., \& Dari, R. W. (2020, September). Regression of Science Process Skills On Critical Thinking Skills In Two Junior High Schools In Jambi City. JIPF (JURNAL ILMU PENDIDIKAN FISIKA), 5(3), 177-186.

Darmaji, Kurniawan, D. A., Astalini, \& Nasih, N. R. (2019). Persepsi Mahasiswa pada Penuntun Praktikum Fisika. Jurnal Pendidikan, 4(4), 516523.

Darmaji, Kurniawan, D. A., Parasdila, H., \& Irdianti. (2018). Deskripsi Keterampilan Proses Sains Mahasiswa pada Materi Termodinamika. Berkala Ilmiah Pendidikan fisika, 6(3), 345353.

Dwijanti, D. (2014). Pembelajaran Fisika Menggunakan SEA Berbantuan Games untuk Mengembangkan Karakter Siswa SMP. Unnes Physics Education Journal, 3(1), 23-29.

Ariananda, E. S., Hasan, S., \& Rakhman, M. (2014). Pengaruh Kedisiplinan Siswa di Sekolah terhadap Prestasi Belajar Siswa Teknik Pendingin. Journal of Mechanical Engineering Education. 1(2), 233-238.

Gunawan, C. (2020). Mahir Menguasai SPSS Panduan Praktis Mengolah Data Penelitian New Edition Buku untuk Orang yang (Merasa) Tidak Bisa dan Tidak Suka Statistika. Sleman: CV. Budi Utama.

Hamdi, S. A., \& Bahruddin, E. (2014). Metode Penelitian Kuantitatif Aplikasi dalam Pendidikan. Yogyakarta: Deepublish.

Hardisman. (2020). Tanya Jawab Analisis Data. Padang: Guepedia.

Hardiyanti, K., Astalini, \& Kurniawan, D. A. (2018). Sikap Siswa terhadap Mata
Pelajaran Fisika di SMA Negeri 5 Muaro Jambi. Edufisika, 3(2), 1-11.

Haryono, S. (2016). Pengaruh Kedisiplinan Siswa dan Motivasi Belajar terhadap Prestasi Belajar Siswa pada Mata Pelajaran Ekonomi. Faktor Jurnal Ilmiah Kependidikan. 3(3), 261-274.

Hatmoko, A. D. (2017). Tingkat Kedisiplinan terhadap Tata Tertib. Skripsi: Universitas Sanata Dharma.

Hendri, M., Pramudya, L., \& Pratiwi, N. I. (2019, Juni). Analisis Hubungan Karakter Semangat Kebangsaan dengan Hasil Belajar. Jurnal Pembangunan dan Pendidikan: Fondasi dan Aplikasi, 7(1), 1-8.

Hermawan, A. (2005). Penelitian Bisnis Paradigma Kuantitatif. Jakarta: PT Grasindo.

Kurniawan, D. A., Astalini, \& Sari, D. K. (2019, June). An Evaluation Analysis of Students' Attitude Towards. Jurnal Penelitian dan Evaluasi Pendidikan, 23(1), 26-35.

Kurniawan, D. A., Astalini, Kurniawan, N., \& Anggraini, L. (2019). Sikap Siswa terhadap IPA Berdasarkan Investigasi dan Korelasi: Kesenangan Belajar dan Minat Meluangkan Waktu pada IPA. Science Education Journal, 3(1), 1-13.

Maison, Astalini, Kurniawan, D. A., \& Sholihah, L. R. (2018). Deskripsi Sikap Siswa SMA Negeri pada Mata Pelajaran Fisika. EDUSAINS, 10(1), 160-167.

Maison, Astalini, Sholihah, L. R., \& Kurniawan, D. A. (2018). Deskripsi Sikap Siswa SMA Negeri 3 Muaro Jambi terhadap Mata Pelajaran Fisika. Edusains.

Maison, Darmaji, Kurniawan, D. A., Dewi, U. P., \& Kartina, L. (2019, Desember). Analysis of Science Process Skills in Physics Education. Jurnal Penelitian dan Evaluasi Pendidikan, 23(2), 197205.

Mayasari, H., Syamsurizal, \& Maison. (2015). Pengembangan Lembar Kerja Siswa (LKS) Berbasis Karakter Melalui Pendekatan Saintifik pada 
Materi Fluida Statistik untuk Sekolah Menengah Atas. Edu-Sains, 4(2), 3036.

Ningsi, A. P., \& Nasih, N. R. (2020). Mendeskripsikan Keterampilan Proses Sains Mahasiswa. EKSAKTA : Jurnal Penelitian dan Pembelajaran MIPA, 5(1), 35-54.

Pathoni, H., Rohati, \& Nazarudin. (2015, November). Peningkatan Pemahaman Konsep Fisika dan Aktifitas. Jurnal Inovasi dan Pembelajaran Fisika, 2(2), 119-122.

Purwanto, A. E., Hendri, M., \& Susanti, N. (2016, Juni). Studi Perbandingan Hasil Belajar Siswa Menggunakan Media Phet. Jurnal EduFisika, 1(1), 22-27.

Putri, A. R., Maison, \& Darmaji. (2018, Desember). Kerjasama dan Kekompakan Siswa dalam Pembelajaran Fisika di Kelas XII. Edufisika, 3(2), 32-40.

Rijal, S., \& Bachtiar, S. (2015). Hubungan antara Sikap, Kemandirian Belajar, dan Gaya Belajar dengan Hasil Belajar Kognitif Siswa. Jurnal BIOEDUKATIKA, 3(2), 15-20.

Sahab, A. (2012). Buku Ajar Analisis Kuantitatif Ilmu Politik dengan SPSS. Surabaya: Airlangga University Press.

Santoso, S. (2010). Statistik Multivariat. Jakarta: PT elex Media Komputindo.

Simanjuntak, S. D. (2020). Statistik Penelitian Pendidikan dengan Aplikasi Ms. Excel dan SPSS. Surabaya: CV. Jakad Media Publishing.

Sobri, M., \& Moerdiyanto. (2014). Pengaruh Kedisiplinan dan Kemandirian Belajar terhadap Hasil Belajar Ekonomi Madrasah Aliyah di Kecamatan Praya. Jurnal Harmoni Sosial, 1(1): 43-56.

Sukarni, W. (2020). Uji Perbandingan Hasil Belajar Siswa Kelas VIII C dan VIII E SMPN 08 Kota Jambi. Jurnal Profesi Keguruan, 6(1), 29-35.

Utama, Z., Maison, \& Syarkowi, A. (2018, April). Analisis Kemampuan Bernalar Siswa SMA Kota Jambi. Jurnal
Penelitian Pembelajaran Fisika, 9(1), $1-5$.

Waluya, B. (2009). Menyelami Fenomena Sosial di Masyarakat. Jakarta: PT Pribumi Mekar. 